\title{
Synthesis of Zinc Sulfide Nanoparticles by Chemical Coprecipitation Method and its Bactericidal Activity Application
}

\author{
Razhan S. Othman ${ }^{1 *}$, Rebaz A. Omar', Karzan A. Omar², Aqeel I. Gheni ${ }^{3}$, Rekar Q. Ahmad ${ }^{4}$, \\ Sheyma M. Salih ${ }^{4}$, Avan N. Hassan ${ }^{4}$ \\ ${ }^{1}$ Department of Medical Laboratory Technique, Shaqlawa Technical Institute, Erbil Polytechnic University, Erbil, Kurdistan Region, Iraq, \\ ${ }^{2}$ Department of Chemistry, Faculty of Science and Health, Koya University, Koya, Kurdistan Region, Iraq, ${ }^{3}$ Department of Medical Microbiology, \\ Faculty of Science and Health, Koya University, Koya, Kurdistan Region, Iraq, ${ }^{4}$ Department of Chemistry, Soran University, Soran, Kurdistan \\ Region, Iraq
}

\section{*Corresponding author: \\ Razhan S. Othman, \\ Department of Medical \\ Laboratory Technique, \\ Shaqlawa Technical Institute, Erbil Polytechnic University, \\ Erbil, Kurdistan \\ Region - F.R. Iraq. \\ Phone: 00964-7504907751. \\ E-mail: razhansalah@epu. \\ edu.iq}

Received: 05 September 2018 Accepted: 15 April 2019

Published: 01 December 2019

\section{DOI}

10.25156/pti.V9n2y2019.pp156-160

\section{A B S T R A C T}

A particle of zinc sulfide $(\mathrm{ZnS})$ was synthesized by the chemical coprecipitation method using zinc sulfate heptahydrate $\left(\mathrm{ZnSO}_{4}\right)$, ammonium sulfate $\left(\mathrm{NH}_{4}\right)_{2} \mathrm{SO}_{4}$ as a reactant, and thiourea as a stabilizer and capping agent. The optioned product characterized by electron dispersive $\mathrm{X}$-ray spectroscopy that exhibits the presence of $\mathrm{Zn}$ and $\mathrm{S}$ elements. The average particle size of the $\mathrm{ZnS}$ nanoparticles determined using $X$-ray diffraction is about $4.9 \mathrm{~nm}$. The ultraviolet-visible spectroscopy showed the blue shift in wavelength and the band gap was $4.33 \mathrm{eV}$, the surface morphology of the synthesized ZnS nanoparticles powder was studied by scan electron microscopy which was showed the irregular and some spherical shapes of ZnS in a nanosized range. The Fourier-transform infrared spectroscopy observed an absorption peck at 657.73 and $613.36 \mathrm{~cm}^{-1}$ that were assigned to the stretching mods of the Zn-S band. The different amounts of ZnS nanoparticle were applied as bactericidal against Staphylococcus aureus by disk diffusion method. It displayed activity against $S$. aureus bacteria, which was carried out in the absence of irradiation.

Keywords: Band gap; Coprecipitation method; Nanoparticle; Staphylococcus aureus; Zinc sulfide

\section{INTRODUCTION}

Zinc sulfide $(\mathrm{ZnS})$ nanoparticles have the abilities for applications in regions such as non-straight optical devices, rapid optical switches, and antibacterial agent and they have been considered widely (Jayalakshmi and Rao, 2006). As of late, there has been impressive enthusiasm for semiconductors of nanometer measurements because of the quantum estimate impact that they show that $\mathrm{ZnS}$ has several nanostructures such as nanobelts, nanocrystals, and nanowires display fantastic electronic and optical performances than the bulk $\mathrm{ZnS}$ material because of the three-dimensional electrons and gaps restriction in a little volume (Behboudnia et al., 2005). Nanoparticles of $\mathrm{ZnS}$ can be synthesized by various methods while the chemical method is one of the most important method due to its simplicity. Recently using metal nanoparticles and metal nanocomposites as antimicrobials agent (Omar et al., 2016a) interested by researchers due to the control of microbial development has turned out to be progressively troublesome inferable from the protection offered by organisms against ordinary hostile to microbial operators. The utilization of metal and polymer nanoparticles and their nanocomposites such as $\mathrm{Ag}$ nanocomposite, $\mathrm{ZnO}$, and $\mathrm{Zn}$ nanocomposite (Dunnill et al., 2009, Bai et al., 2011 and Omar et al., 2016b) for anti-microorganisms action has been effectively exhibited as of late. The silver and $\mathrm{ZnO}$ nanoparticles (Perelshtein et al., 2013) become as novel antibacterial specialists as these particles are set up by straightforward and financially savvy systems such as compound precipitation with great control over the surface zone, molecule sizes, and stoichiometry. Recently, the utilization of $\mathrm{ZnS}$ nanoparticles as an antibacterial agent reported by (Masalha et al., 2001), which described that the Staphylococcus aureus is a Gram-positive facultative aerobe has ability to grow in the absence of oxygen by fermentation or using an alternative electron acceptor. The S. aureus shows up as staphylococci (grape-like groups), they can be seen through a magnifying lens, they are showing vast, round, brilliant yellow provinces due to hemolysis of blood agar medium which has been used as a medium developer (Ryan et al., 2004). Assessed 20-30\% 
of the human populace is long-haul bearers of $S$. aureus (Kluytmans et al., 1997, and Tong et al., 2015) which can be found as a feature of the typical skin verdure, in the nostrils, and as an ordinary tenant of the lower conceptive tract of women. It is as yet one of the five most basic reasons for healing facility procured diseases and is regularly the reason for wound contaminations following (Harris et al., 2002). In recent years, around 500,000 patients in healing facilities of the USA get a staphylococcal disease, mostly by S. (Bowrsox et al., 1999). Up to 50,000 passing every year in the United states of America are connected with $S$. aureus infections (Schlecht et al., 2015). The antibacterial impact and instrument activity of a silver particle arrangement that was electrically created were examined for $S$. aureus and Escherichia coli by breaking down the development, morphology, and ultrastructure of the bacterial cells following treatment with the silver particle solution (Jung et al., 2008) silver particles caused stamped restraint of bacterial development and were saved in the vacuole and cell divider as (Tang and Cameron, 1996). They restrained cell division and harmed the cell envelope and substance of microscopic organisms, bacterial cells expanded in the estimate, and the cytoplasmic film, cytoplasmic substance, and external cell layers all displayed basic variations from the norm. At last, silver particles connect with nucleic (Thomas et al., 2010).

In the present study, the different amounts of the $\mathrm{ZnS}$ nanoparticles have been used against $S$. aureus Grampositive bacteria which were carried out in the absence of irradiation.

\section{MATERIALS AND METHODS}

All the chemicals are used in this research which were provided by Soran University in Kurdistan Region-Iraq. The analytical reagents grade of Zinc sulfate heptahydrate $\left(\mathrm{ZnSO}_{4} .7 \mathrm{H}_{2} \mathrm{O}\right)$, ammonium sulfate $\left(\mathrm{NH}_{4} 2 \mathrm{SO}_{4}\right)$, methanol, and thiourea was used. All metal solutions were prepared from distilled water.

\section{Synthesis of ZnS Nanoparticles}

Zinc sulfide nanoparticles were synthesized at room temperature using the solution growth wet chemical method. The reaction matrix employed in our study consisted of analytical reagent grade $\mathrm{ZnSO}_{4} \cdot 7 \mathrm{H}_{2} \mathrm{O}$, ammonium sulfate, and thiourea in 1:1.5:1.5 molar ratios. Zinc sulfate heptahydrate and ammonium sulfate were mixed in $50 \mathrm{ml}$ of distilled water. Ammonia was added to it until the formation of clear metallic complexes. The $\mathrm{pH}$ was kept at 9.5. Then, thiourea was dissolved in 50 $\mathrm{ml}$ of prepared solution. The prepared sample of $\mathrm{ZnS}$ nanoparticles was washed several times with distilled water and methanol to remove impurities (Harvey, 2000).

\section{Bactericidal Performance}

The antibacterial activity of 0.01 and $0.06 \mathrm{~g}$ of $\mathrm{ZnS}$ nanoparticles was performed by disk diffusion method as described by Kirby-Bauer. Loop full growths from bacterial isolate were inoculated into nutrient broth incubated at $37^{\circ} \mathrm{C}$ for $18-24 \mathrm{~h}$. The bacterial suspensions were diluted with normal saline (Macij et al., 1992), the solute concentration in isotonic solution remains the same both (inside and outside) of the microbial cell and cells keep at their osmotic pressure. Adjust the turbidity and compare with standard tube (McFarland number 0.5) to yield a uniform suspension. A cotton swab was dipped and streaks into adjustment suspension the entire Mueller-Hinton agar. Sample pleats or discs were gently pressed on the surface of the agar. The plates were incubated overnight at $37^{\circ} \mathrm{C}$ while the antibiotic diffuses from the disc into the agar (Nicole et al., 2008). After incubation, the plates were examined for the presence of zones of non-growth zone.

\section{RESULTS}

\section{Ultraviolet (UV)-visible Spectroscopy of ZnS Nanoparticles}

The UV-visible spectroscopy measurement was carried out using a double-beam spectrophotometer carry 100 scans and operated in the range of $280-400 \mathrm{~nm}$ at a resolution of $2.0 \mathrm{~nm}$ at chemistry department of Koya University. The photoabsorption ability of the $\mathrm{ZnS}$ nanoparticles was detected by the UV-visible spectrum, as shown in Figure 1. The $\mathrm{ZnS}$ nanoparticles showed strong absorption at the wavelength of $286.12 \mathrm{~nm}$. The band gap energy $(\mathrm{Eg})$ of the nanoparticles was concluded by the formula: $\mathrm{Eg}=1240 / \lambda \mathrm{g}$, where $\lambda \mathrm{g}$ is the wavelength. The wavelength of the absorption edge of the synthesized $\mathrm{ZnS}$ nanoparticles was $268.16 \mathrm{~nm}$. Thus, the band gap energy estimated from the absorption edge was about $4.33 \mathrm{eV}$

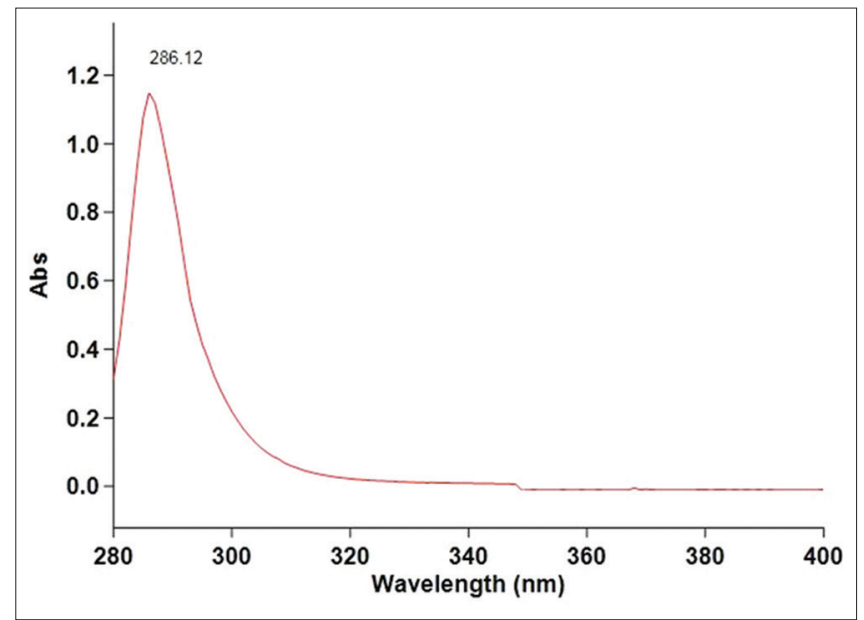

Figure 1: The ultraviolet-visible spectrum of zinc sulfide nanoparticles 
which indicates that the $\mathrm{ZnS}$ particle suspension has a high ability to absorb UV light.

\section{Fourier Transform Infrared (FTIR) Radiation Spectrum of ZnS Nanoparticles}

The FTIR spectrum of $\mathrm{ZnS}$ nanoparticles analysis was carried out, using IR-Affinity 1, Shimadzu makes FTIR spectrometer in a wavenumber range from 400 to $4000 \mathrm{~cm}^{-1}$ at Chemistry Department of Salahaddin University, is shown in Figure 2. ZnS nanoparticles absorption peak observed at 657.73 and $613.36 \mathrm{~cm}^{-1}$ are assigned to the stretching modes of $\mathrm{Zn}-\mathrm{S}$. The bands exhibited from $3275.13 \mathrm{~cm}^{-1}$ and $3190.26 \mathrm{~cm}^{-1}$ are representing $\mathrm{O}-\mathrm{H}$ of water molecules on the surface of nanoparticles and $\mathrm{N}-\mathrm{H}$ stretching of thiourea, whereas the vibration bands observed at $1683.86 \mathrm{~cm}^{-1}$ and $1429.25 \mathrm{~cm}^{-1}$ are the typical vibration bands of $\mathrm{C}=\mathrm{O}$ and $\mathrm{C}-\mathrm{H}(\mathrm{CH} 3)$ bending.

The vibrational bands at $1203.58-1139.39 \mathrm{~cm}^{-1}$ are probably attributed C-H stretching and band at 979.84 assigned to $\mathrm{C}-\mathrm{H}$ bending. The weak bands at 1089.70 and 1037.70 are probably attributed to $\mathrm{C}-\mathrm{O}$ stretching. The peak at $480 \mathrm{~cm}^{-1}$ is assigned to $\mathrm{NH}_{2}$ symmetric stretching vibration.

\section{Scanning Electron Microscopy}

The surface morphology of the synthesized $\mathrm{ZnS}$ nanoparticles powder was studied by scanning electron microscopy at Soran University, as shown in Figure 3a-d at different magnifications. The instrumental parameters, accelerating voltage, spot size, and magnification and working distances are indicated. The scan electron microscopy (SEM) micrograph of $\mathrm{ZnS}$ nanoparticles size exhibited the irregular and some spherical shapes of particles in a nanosized range with the large amount of agglomeration which may occur during the synthesis process and calculations of nanosamples at $100^{\circ} \mathrm{C}$. The electron dispersive X-ray spectrum of the prepared $\mathrm{ZnS}$ nanoparticles is shown in Figure 4. It shows the presence of $\mathrm{Zn}$ and $\mathrm{S}$ elements in preparing nanoparticles.

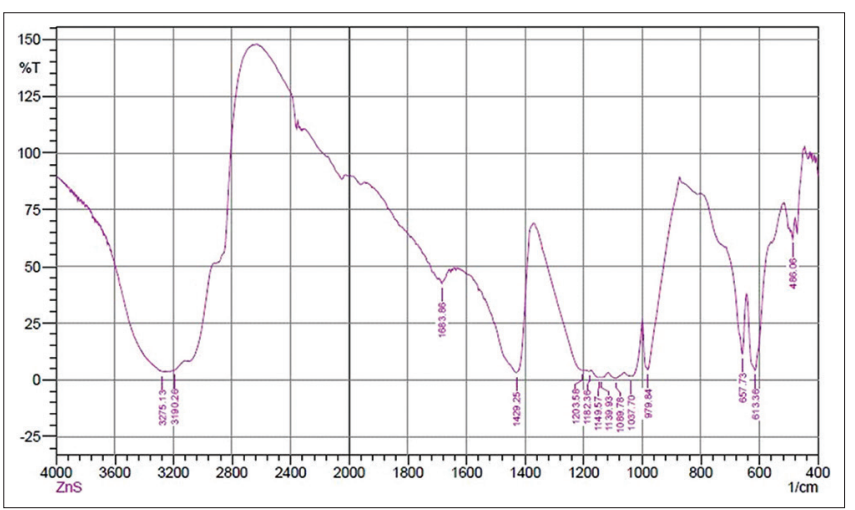

Figure 2: Fourier transform infrared spectrum for prepared zinc sulfide nanoparticle
X-ray Diffraction (XRD) Analysis of ZnS Nanoparticles The synthesized $\mathrm{ZnS}$ nanoparticles were characterized using XRD carried out at Physics Department of Koya University. XRD was collected using a Rigaku Mini with $\mathrm{Cu} \mathrm{K} \alpha$ radiation $(\lambda=0.1541 \mathrm{~nm})$. The diffractograms were recorded in a range of $10-80^{\circ}$. Figure 5 shows XRD study of $\mathrm{ZnS}$ nanoparticles synthesized by chemical coprecipitation method. The average particle sizes of synthesized $\mathrm{ZnS}$ nanoparticles were calculated using the Debye-Scherer formula.

$$
\mathrm{D}=\frac{\mathrm{k} \lambda}{\beta \operatorname{Cos} \theta}
$$

Where, " $\mathrm{D}$ " is average particle size, " $\mathrm{K}$ " is the shape factor, " $\lambda$ " is the $\mathrm{X}$-ray wavelength $(0.1541 \mathrm{~nm})$, " $\theta$ " is the Bragg's angle in radians, and " $\beta$ " the full width at maximum in
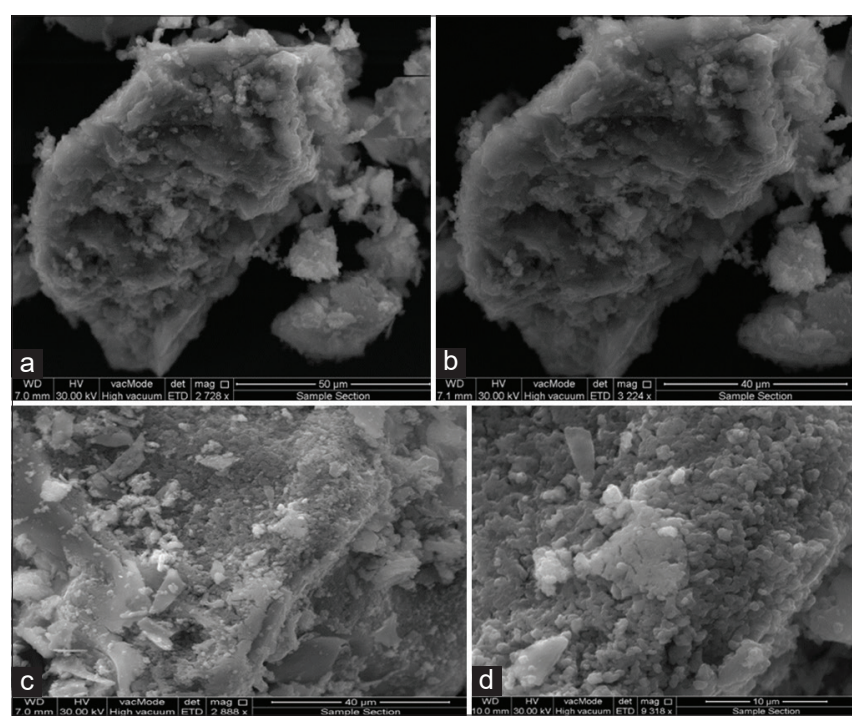

Figure 3: Scan electron microscopy for prepared zinc sulfide nanoparticle at (a) $\times 2728$, (b) $\times 3224$, (c) $\times 2888$, (d) $\times 9318$

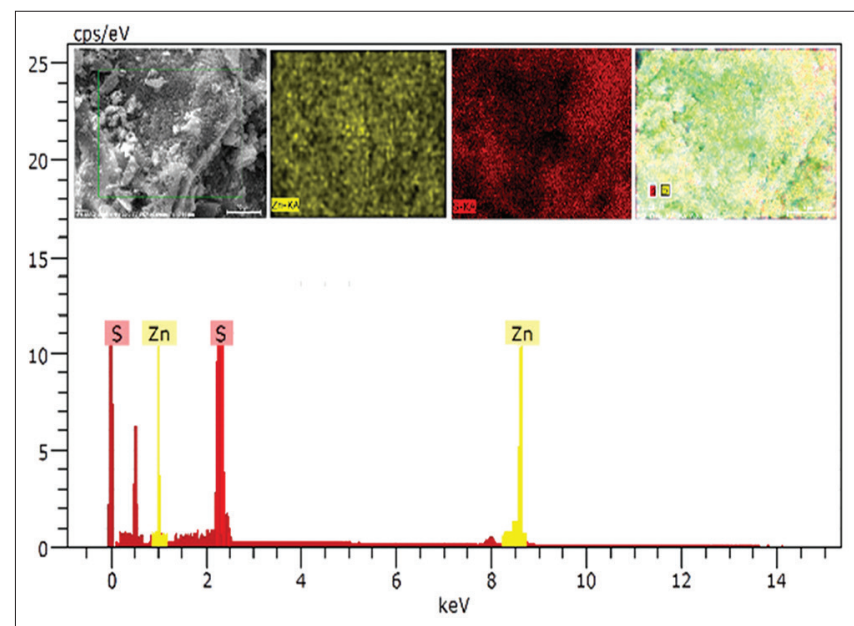

Figure 4: Electron dispersive $X$-ray image of zinc sulfide nanoparticles 


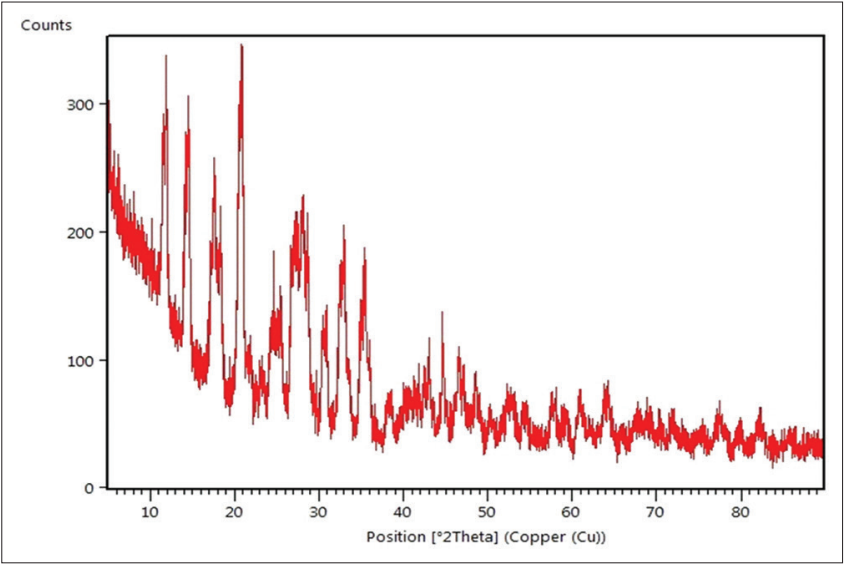

Figure 5: X-ray diffraction pattern of synthesized zinc sulfide nanoparticle

radians. The average particle size is calculated using the above formula is $4.9 \mathrm{~nm}$.

\section{Calculation of ZnS Nanoparticle Size from UV-visible Spectra}

An absorption spectrum as shown in Figures 1 can be obtained. The absorption peak appears at $286.12 \mathrm{~nm}$. From the excitation peak position $286.12 \mathrm{~nm}$, the band gap of $\mathrm{ZnS}$ nanoparticles can be determined using $\mathrm{E}=1240 / \lambda$. The band gap for $\mathrm{ZnS}$ nanoparticles is $4.33 \mathrm{ev}$ and the particle size of $\mathrm{ZnS}$ nanoparticles can be calculated by the following equation (1),

$$
\mathrm{R}=\frac{\sqrt{2 \pi^{2} \mathrm{~h}^{2} \mathrm{E}_{\text {Bulk }}}}{\mathrm{m}^{*}\left(\mathrm{E}_{\text {Nano }}^{2}-\mathrm{E}_{\text {Bulk }}^{2}\right)}
$$

Where, $\mathrm{R}$ is the radius of the quantum size nanoparticles of $\mathrm{ZnS}$ which has bulk band gap energy $\mathrm{Eg}$ of $3.68 \mathrm{eV}$ and the effectively reduced mass is me* $=3.64 \times 10^{-31} \mathrm{~kg}$. The size of $\mathrm{ZnS}$ nanoparticles has been calculated as $10.6 \mathrm{~nm}$.

\section{Bactericidal Activity}

The bactericidal activity of $\mathrm{ZnS}$ nanoparticles was tested against $S$. aureus, for qualitative measurement of bactericidal activity, the precipitated $\mathrm{ZnS}$ nanoparticles were cut into $6-8 \mathrm{~mm}$ diameter with concentrations $(0.01 \mathrm{~g}$ and $0.06 \mathrm{~g})$. The modified agar diffusion assay used for disc tests. The plates were examined for possible clear zones after incubation at the $37^{\circ} \mathrm{C}$ for $24 \mathrm{~h}$. The presence of a clear zone around the circular disc on the plate medium was recorded as an inhibition against the microbial species, which indicated that the $\mathrm{ZnS}$ nanoparticle has antibacterial activity against $S$. aureus bacteria, as shown in Figure 6.

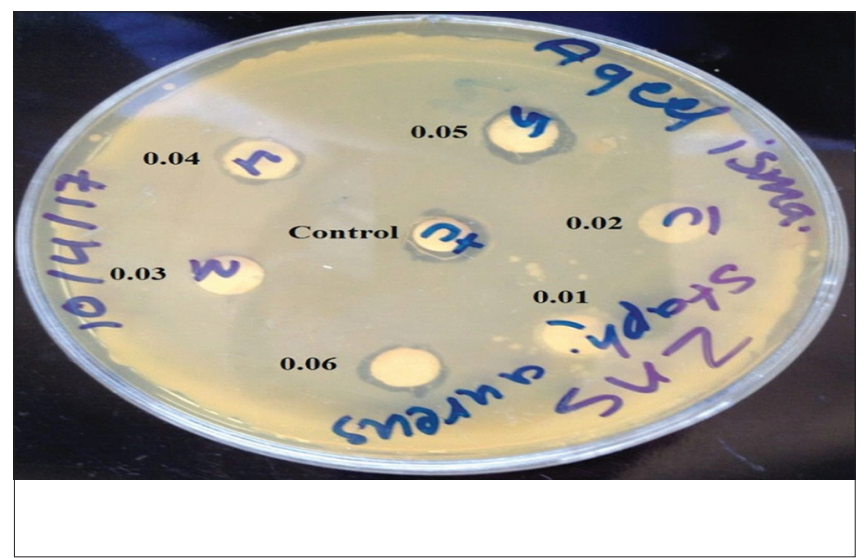

Figure 6: Antibacterial activity of different amounts of zinc sulfide nanoparticles Staphylococcus aureus

\section{DISCUSSION}

The results showed that utilizing the verity analytical reagent of $\mathrm{ZnSO}_{4} \cdot 7 \mathrm{H}_{2} \mathrm{O}$, ammonium sulfate, and thiourea for preparing $\mathrm{ZnS}$ nanoparticles with $4.9 \mathrm{~nm}$ is synthesized by chemical coprecipitation method. The prepared nanoparticles have an irregular shape along with some agglomeration caused during the synthetic process and indicated by scanning electronic miscopy. Although, the majority of the nanoparticles have round shape. Some are agglomerated and the shapes could not be resolved (Chandran et al., 2010). In the present study, band gap vitality of $\mathrm{ZnS}$ evaluated from the retention edge was about $4.33 \mathrm{eV}$ which shows that the $\mathrm{ZnS}$ molecule suspension has a high capacity to ingest UV light. This is higher than that of bulk $\mathrm{ZnS}$ demonstrating the presence of solid quantum forced (Chandran et al., 2010). As well proved that $\mathrm{ZnS}$ is a critical inorganic semiconductor with a wide range of band gap from 3.5 to $3.7 \mathrm{eV}$. This compound has a proper potential for application in different fields, for example, natural naming, sun-based cells, phosphors, photograph conductors, field impact optical sensors, transistors, photocatalysts, electroluminescent materials, and other light discharging materials (Jamieson et al., 2007; Wang et al., 2011).

Furthermore, the UV-visible spectroscopy, infrared spectroscopy, and XRDs are used for indicating and conforming prepared nanoparticles. The prepared nanoparticles have been used as an antibacterial against $S$. aureus bacteria. Finally, the maximum antibacterial activities of prepared nanoparticle of $\mathrm{ZnS}$ were found at concentration of 0.05 and $0.06 \mathrm{mg} / \mathrm{ml}$. The antibacterial activity of the prepared nanoparticles revealed that the $\mathrm{ZnS}$ nanoparticles are more effective to $S$. aureus bacteria than the $\mathrm{Zn} /$ nylon nanocomposite (Omar et al., 2016c) and less activity on comparing to the zinc oxide nanoparticles 
(Nicole et al., 2008) and its nanocomposites (Omar et al., 2016a).

\section{CONCLUSIONS}

ZnS nanoparticle Q-Dot has been synthesized successfully using chemical coprecipitation method, the FTIR study showed the chemical bonding of the $\mathrm{Zn}-\mathrm{S}$ and the average particle size was determined using XRD technique, the particle size of the $\mathrm{ZnS}$ prepared is found to be $4.9 \mathrm{~nm}$, the optical band gap of the $\mathrm{ZnS}$ nanoparticle was characterized using UV-visible spectroscopy that exhibits a blue shift absorption from the bulk $\mathrm{ZnS}$ due to the quantum confinement effect with the band gap of $4.33 \mathrm{eV}$. Surface morphology of the synthesized nanoparticles was studied using SEM technique which showed irregular and some spherical shapes of particles in nanosized range. The different amount of $\mathrm{ZnS}$ nanoparticle was applied as an antibacterial against $S$. aureus by disk diffusion method. It shows activity against $S$. aureus bacteria, which was carried out in the absence of irradiation.

\section{REFERENCES}

Bai, H., Z. Liu and D. D. Sun. 2011. Hierarchical ZnO/Cu "corn-like" materials with high photodegradation and antibacterial capability under visible light. J. Phys. Chem. Chem. Phys. 13: 6205-6210.

Behboudnia, M., M. H. Majlesara and B. Khanbabaee. 2005. Preparation of ZnS nanorods by ultrasonic waves. J. Mater. Sci. Eng. 122(2): 160-163.

Bowersox, J. 1999. Experimental Staph Vaccine Broadly Protective in Animal Studies, NIH, Archived the Original on 5 May 2007. https://www.en.wikipedia.org/wiki/Staphylococcus_aureus\#cite_ note-NIH-10. [Last accessed on 2007 Jul 28].

Chandran, A., N. Francis, T. Jose and K. C. George. 2010. Synthesis, structural characterization and optical bandgap determination of ZnS nanoparticles. Acad. Rev. 17(1-2): 17-21.

Dunnill, C. W., Z. A. Aiken, A. Kafizas, J. Pratten, M. Wilson, D. J. Morgan and I. P. Parkin. 2009. White light induced photocatalytic activity of sulfur-doped $\mathrm{TiO}_{2}$ thin films and their potential for antibacterial application. J. Mater. Chem. 19: 8747-8754.

Harris, L.G., J. Foster and R. G. Richard. 2002. An introduction to Staphylococcus aureus, and technique for identifying and quantifying $S$. aureus adhesions in relation to adhesion to biomaterials. J. Eur. Cells Mater. 4: 39-60.

Harvey, D. 2000. Modern Analytical Chemistry. $1^{\text {st }}$ ed. McGraw-Hill, Dubuque, IA.

Jamieson, T., R. Bakhshi, D. Petrova, R. Pocock, M. Imani and A. M. Seifalian. 2007. Biological applications of quantum dots. J. Biomater. 28(31): 4717-4732.
Jayalakshmi, M. and M. M. Rao. 2006. Synthesis of zinc sulphide nanoparticles by thiourea hydrolysis and their characterization for electrochemical capacitor applications. J. Power Sources. 157: 624-629.

Jung, W. K., H. C. Koo, K. W. Kim, S. Shin, S. Kim and Y. H. Park. 2008. Antibacterial activity and mechanism of action of the silver ion in Staphylococcus aureus and Escherichia coli. Appl. Environ. Microbiol. 74: 2171-2178.

Kluytmans, J., A. Van Belkum and H. Verbrugh. 1997. Nasal carriage of Staphylococcus aureus: Epidemiology, underlying mechanisms, and associated risks. J. Clin. Microbiol. Rev. 10: 505-520.

Maciej, Z., S. M. Paul, F. Tyan and S. H. Geraldine. 1992. Quantitative separation of bacteria in saline solution using lanthanide $\operatorname{Er}(I I 1)$ and a magnetic field. J. Gen. Microbiol. 138: 63-68.

Masalha, M., I. Borovok, R. Schreiber, Y. Aharonowitz and G. Cohen. 2001. Analysis of transcription of the Staphylococcus aureus aerobic class $\mathrm{Ib}$ and anaerobic class III ribonucleotide reductase genes in response to oxygen. J. Bacteriol. 183: 7260-7272.

Nicole, J., R. Binata, T. R. Koodali and C. M. Adhar. 2008. Antibacterial activity of $\mathrm{ZnO}$ nanoparticle suspensions on a broad spectrum of microorganisms. FEMS Microbiol. Lett. 279(1): 71-76.

Omar, K., B. I. Meena and S. A. Muhammed. 2016a. Study on the activity of $\mathrm{ZnO}-\mathrm{SnO}_{2}$ nanocomposite against bacteria and fungi. J. Physicochem. Probl. Miner. Proc. 52: 754-766.

Omar, R. A., A. I. Gheni and K. A. Omar. 2016c. Antibacterial activity of $\mathrm{Zn} /$ Nylon nanocomposite against Escherichia coli and Staphylococcus aureus. Indian J. Nat. Sci. 6(36): 976-997.

Omar, R. A., A. K. Smail and K. A. Omar. 2016b. Study on the activity of Ag/Nylon 6, 10 nanocomposite against Escherichia coli. Int. J. Curr. Microbiol. Appl. Sci. 5: 935-941.

Perelshtein, I., E. Ruderman, N. Perkas, T. Tzanov, J. Beddow, E. Joyce, T. J. Mason, M. Blanes, K. Mollá and A. Patlolla. 2013. Chitosan and chitosan ZnO-based complex nanoparticles: Formation, characterization, and antibacterial activity. J. Mater. Chem. B. 1: 1968-1976.

Ryan, K. J. and C. G. Ray. 2004. Sherris Medical Microbiology. $4^{\text {th }}$ ed. McGraw Hill, New York.

Schlecht, L. M., B. M. Peters, B. P. Krom, J. A. Freiberg, G. M. Hänsch, S. G. Filler, M. A. Jabra-Rizk and M. E. Shirtliff. 2015. Systemic Staphylococcus aureus infection mediated by Candida albicans hyphal invasion of mucosal tissue. J. Microbiol. 161: 168-181.

Tang, W. and D. C. Cameron. 1996. Electroluminescent zinc sulphide devices produced by sol-gel processing. Thin Solid Films. 280: 221-226.

Thomas, J. S., K. Daniel. and W. Suzanne. 2010. The bacterial cell envelope. Cold Spring Harb. Perspect. Biol. 2(5): a000414.

Tong, S. Y., J. S. Davis, E. Eichenberger, T. L. Holland and V. G. Fowler. 2015. "Staphylococcus aureus infections: Epidemiology, pathophysiology, clinical manifestations, and management. J. Clin. Microbiol. Rev. 28: 603-661.

Wang, C. F., B. Hu, H. H. Yi and W. B. Li. 2011. Structure and photoluminescence properties of ZnS films grown on porous $\mathrm{Si}$ substrates. J. Opt. Laser Technol. 43(8): 1453-1457. 